\title{
INCLUDING FUNCTIONAL MODELS OF BIOLOGICAL PHENOMENA AS DESIGN STIMULI
}

\author{
V. Vakili, I. Chiu, L.H. Shu* \\ Dept. of Mechanical and Industrial Engineering \\ University of Toronto \\ 5 King's College Road \\ Toronto, ON M5S 3G8 Canada \\ *Corresponding author email: shu@mie.utoronto.ca
}

\author{
D.A. McAdams, R.B. Stone \\ Design Engineering Laboratory \\ University of Missouri-Rolla \\ Rolla, Missouri 65409 USA
}

\begin{abstract}
This work explores the representation of biological phenomena as stimuli to designers for biomimetic design. We describe a study where participants were asked to solve a micro-assembly problem given a set of biological representations of leaf abscission for inspiration. The visual aids presented to the designers are investigated, and the use of functional models of biological phenomena in particular is critiqued. The designs resulting from the study are classified and theories drawn as to possible influences of the biological representations. Observations, retrospective conversations with participants, and analogical reasoning classifications are used to determine positive qualities as well as areas for improvement in representation of the biological domain. Findings suggest that designers need an explicit list of all possible inherent biological strategies, previously extracted using function structures with objective graph grammar rules. Challenges specific to this type of study are discussed, and possible improvement of representative aids are outlined.
\end{abstract}

\section{INTRODUCTION}

\section{Motivation}

Design is a cognitive task, susceptible to the stimuli and other information presented to the designer. Biomimetic design - where biological phenomena are used as stimuli or sources of analogy - has been shown to enhance the problem-solving process [Vakili and Shu 2001; Shu et al. 2006]. An important fact is that the manner of presentation of images and text describing biological phenomena affect the designer's understanding of the phenomena, and therefore his or her problem-solving success.
A standard, comprehensive, clear and learnable schema of model representation is needed so engineers can extract biological strategies. The use of functional models is seen as an appropriate approach to articulate biological strategies to designers. A related topic is the growing research in capturing empirically derived design knowledge from consumer products, and cataloging these in a Design Repository [Kurtoglu et. al. 2005]. This work asserts "[knowledge] representation is crucial because it establishes the limits of the search space and the scope of design complexity." The Functional Basis of Stone and Wood [2000] is the model schema for the function structure diagram used in this study.

The use of formal function structures is likely transferable to the organization and presentation of complex biological models, a step toward standardization and ease of compilation [Sridharan and Campbell 2004]. This has motivated the exploration of functional modeling of biological phenomena in a similar way to the modeling of consumer products. It is hoped that functional modeling will lead to more powerful techniques for designers to extract strategies from biological phenomena.

\section{Objectives}

This study explores the features of biological representations that help or deter engineers in biomimetic concept generation. In particular, it explores the use of a function structure based on standard schema and language basis as a functional model for a biological phenomenon. The insights taken from this small-scale, experimental study will guide future research in the area of biological representation and how it is used by designers. 


\section{NOMENCLATURE}

\begin{tabular}{|c|c|}
\hline $\begin{array}{l}\text { Biomimetic design, or } \\
\text { bio-analogous design }\end{array}$ & $\begin{array}{l}\text { The use of biological phenomena } \\
\text { as analogies to solve engineering } \\
\text { problems. }\end{array}$ \\
\hline Biological representation & $\begin{array}{l}\text { A visuo-textual model that } \\
\text { abstracts a biological phenomenon } \\
\text { for use by designers. }\end{array}$ \\
\hline $\begin{array}{l}\text { Biological strategy } \\
\text { extraction }\end{array}$ & $\begin{array}{l}\text { Identification of how a biological } \\
\text { phenomenon achieves some } \\
\text { purpose, in functional, abstracted } \\
\text { terms. }\end{array}$ \\
\hline Functional model & $\begin{array}{l}\text { Abstract conceptualization of an } \\
\text { artifact, product or system in terms } \\
\text { of its function [Hirtz et al. 2002]. }\end{array}$ \\
\hline Function structure & $\begin{array}{l}\text { A functional model for a particular } \\
\text { artifact, based on functions and } \\
\text { flows, as well as systematic } \\
\text { construction rules [Sridharan and } \\
\text { Campbell 2004]. }\end{array}$ \\
\hline $\begin{array}{l}\text { Similarity types } \\
\text { (The remaining } \\
\text { definitions are taken from } \\
\text { Mak and Shu [2004b].) }\end{array}$ & $\begin{array}{l}\text { Types of similarities between the } \\
\text { biological phenomena and the } \\
\text { concepts developed using them as } \\
\text { design stimuli. }\end{array}$ \\
\hline Analogy & $\begin{array}{l}\text { Implementation of strategies } \\
\text { derived from biological } \\
\text { phenomena without transferring } \\
\text { the biological forms. }\end{array}$ \\
\hline Anomaly & $\begin{array}{l}\text { Implementation that does not } \\
\text { involve apparent similarity } \\
\text { between the concept and the } \\
\text { biological phenomenon; } \\
\text { sometimes based on word } \\
\text { associations. }\end{array}$ \\
\hline Biological transfer & $\begin{array}{l}\text { Not implementing the strategy of } \\
\text { the biological phenomenon, but } \\
\text { fixating on the biological form and } \\
\text { using the actual biological entity } \\
\text { to fulfill an unrelated strategy. }\end{array}$ \\
\hline $\begin{array}{l}\text { Literal } \\
\text { implementation }\end{array}$ & $\begin{array}{l}\text { Implementing the strategy } \\
\text { presented by the biological } \\
\text { phenomenon by having it carried } \\
\text { out by the biological form; a } \\
\text { failure to abstract and separate the } \\
\text { strategy from its form. }\end{array}$ \\
\hline
\end{tabular}

\section{RELATED WORK}

The work presented draws upon the following research:

\section{Biomimetic design}

The work of Vincent and Mann [2002] takes the approach of using existing biomimetic designs and storing the strategies in a database. The method for extracting strategies may lend itself to possible bias by an individual biologist's expertise. We discuss other possible extraction methods that are practical for adoption by designers with no biology expertise. Earlier research on biomimetic design at the University of Toronto focused on the transfer of biological domain knowledge and creativity, demonstrated by case studies [Hacco and Shu 2002; Chiu and Shu 2004]. The challenge remains to find ways to abstract and represent biological phenomena in a way that optimally supports designers.

\section{Functional modeling and systematic extraction of engineering design knowledge}

One possible abstraction method is that of functional modeling, which guides many design activities, two of these being problem decomposition and concept generation [Hirtz et. al. 2002]. Functional modeling is explored in this paper as an aid in biomimetic concept generation. The eventual goal of this work is to incorporate biological information in the Design Repository [Bryant et al. 2005, Kurtoglu et al. 2005], another strategic tool for innovative concept generation. Sridharan and Campbell's work [2004] on function structures shows that systematic grammar rules can be applied to these functional models, making them learnable, consistent, shareable, and computable. In this study, we explore the appropriateness of function structures as learnable representation materials for biomimetic design by analogy.

\section{Observing engineers using design aids}

The methods used in this study include think-aloud sessions and recall interviews with participants. The objective of the study is to gain maximum insight into the designer's problem-solving process; therefore we approached the study from the angle of cognitive psychology. This approach is inspired by Dillon and Sweeney [1988]. Their study used ethnographic observation to determine cognitive requirements of mechanical engineers that would inform the design of CAD applications.

The similarities in the objectives of our study - observing cognitive aspects of design, and using the insights to improve a design tool - suggested a similar approach would be appropriate. In our study, we provide visual and text aids, as they did drawing aids, and observe how they are used during the course of solving an engineering problem. Our observation is not, however, ethnographic because it is done in a laboratory setting with modifications to the natural execution of the design task, such as thinking aloud, time limitation, and a solitary environment.

\section{Think-aloud protocol in design}

Language has been shown to be closely linked to reasoning, and therefore important to the design process [Chiu and Shu 2007]. Think-aloud or verbal reporting was used in this study to obtain insight into the designers' thought processes. 


\section{Case study in microassembly}

Previous work on biomimetic design has included an application to microassembly [Shu et al. 2006], which provides the content for the experiment in this study. The problem in this application is to develop a way of handling a micro-screw that overcomes the sticking effects of surface forces. One analogous biological phenomenon is that of leaf abscission, the process by which leaves fall from plants. In the case study, a feasible physical solution was obtained based on this analogy. Therefore this specific problem as well as analogy was selected for this study.

\section{Classification of designs}

Classification schemes were created by Mak and Shu [2004a, 2004b], one for similarity types (see Nomenclature), and one for accuracy of strategies extracted from biological phenomena. Biomimetic design strives to generate concepts of the similarity type "analogy". Biological phenomena are vulnerable to misinterpretation, especially by novices to biology. This can lead to the extraction of incorrect strategies, which are not representative of the actual mechanism of the biological phenomenon. An incomplete strategy uses a general principle behind the correct strategy, but not the specific strategy itself. These schemes are later discussed in more detail, and used in the analysis of the observations.

\section{STUDY}

The methodology chosen is based in part on that used by Chiu and Shu [2007].

\section{Apparatus}

A work desk was set up with a tripod-mounted video recorder to videotape the workspace. On the workspace were cards with text and images shown in the figures below: one of the problem statement; the text description of leaf abscission, corresponding diagrams and images of leaf abscission, all taken from Purves et al. [2001]; and for the intervention group only, a function structure diagram of leaf abscission (Appendix A). Modifications were made to the source materials to remove some information not relevant to the task.

Participants were also provided with a worksheet pad, pens and a bottle of water, as they were expected to verbalize their thoughts throughout the experiment.

\section{Methodology}

A between-subjects design experiment was used, with an intervention group and a control group, the intervention being the supplementary function structure diagram. In a betweensubjects design experiment, participants only complete the experiment under one condition, e.g., either without the aid of the function structure diagram (control group) or with the aid of the function structure diagram (intervention group). Three female and four male paid participants were senior undergraduate, Master's and Ph.D. students in Mechanical and Industrial Engineering at the University of Toronto.

\section{Challenges in Microassembly}

Challenges specific to microassembly are due to the reduced dimensions involved. Microscopes are required for vision and microgrippers are required for manipulation. At the micro level, surface-related forces, such as electrostatic, Van der Waals and surface tension forces dominate gravitational forces. Such forces are significant for microcomponents-the gravitational forces acting on objects decrease with size while surface forces essentially remain the same or decrease at a lower rate. These surface forces depend on gripper design.

Design Problem: Develop a novel gripper design that overcomes sticking effects that complicate the automated grasping and releasing of microobjects. Develop a grasping and releasing mechanism for microgrippers that overcomes adhesion due to surface forces between components. Address the problem of picking up, correctly positioning and tightening a metal screw of approximately $0.6 \mathrm{~mm}$ diameter.

\section{Figure 1: Problem statement card.}

Although time and resources originally allowed for eight participants, the results of only seven were usable. While the small sample size is not statistically significant, talk-aloud studies often do not involve a large number of participants.

Participants were observed individually as they solved a problem while thinking aloud. A semi-formal recall interview was then performed to gather further insight into the design process. All sessions were recorded, but not all sessions were fully transcribed. The conductor of the study took notes, but was not directly in the participant's view, during sessions. The same conductor then reviewed the session recordings. While currently there are no correlated observations, session notes and recordings are available to be re-analyzed by others.

Participants were given a series of warm-up exercises. First they were asked to think aloud while performing a simple arithmetic addition exercise; next, two recall exercises; and next, to draw a simple diagram representing the inputs and outputs of a familiar device, such as a blender. For the main experiment, they were asked to first read the problem shown in Fig. 1, and then use the text and images from the biological domain to generate a design concept that solved the problem.

Participants were given 30 minutes to address the sticking effects of surface forces between gripper and screw, using abscission as an analogy, while thinking aloud. Again, this problem and its accompanying biological analogy were selected because feasible solutions were known to be possible. 


\section{Observations}

Interview notes, worksheets, and video were reviewed to gather observations. Appendix B contains the full table of observations, including participant background, problem interpretations, and other key factors. Common observations between participants were found and are described below.

\section{Classification of designs}

Classification of designs was done using the method developed by Mak and Shu [2004a, 2004b]. This method highlights the use of the correct strategies presented by the biological phenomenon, and identifies where design concepts are the product of analogous thinking. Table 1 shows the results of the 7 participants in the study.

\section{Auxin affects vegetative growth}

Auxin has many roles in plant development. It affects vegetative growth in several ways, including stimulating the detachment of old leaves from their stems (abscission).

This process, called abscission, is the cause of autumn leaf fall. Leaves consist of a blade and a petiole that attaches the blade to the stem. Abscission results from the breakdown of a specific part of the petiole, the abscission zone (Figure 37.13). If the blade of a leaf is cut off, the petiole falls from the plant more rapidly than if the leaf had remained intact (Figure 37.14). The time of abscission of leaves in nature appears to be determined in part by a decrease in the movement of auxin, produced in the blade, through the petiole.

\section{Figure 2: Text description of abscission (Purves et al., 2001).}

\subsection{When a Leaf is about to Fall}

The breakdown of the abscission zone of the petiole causes the leaf to fall

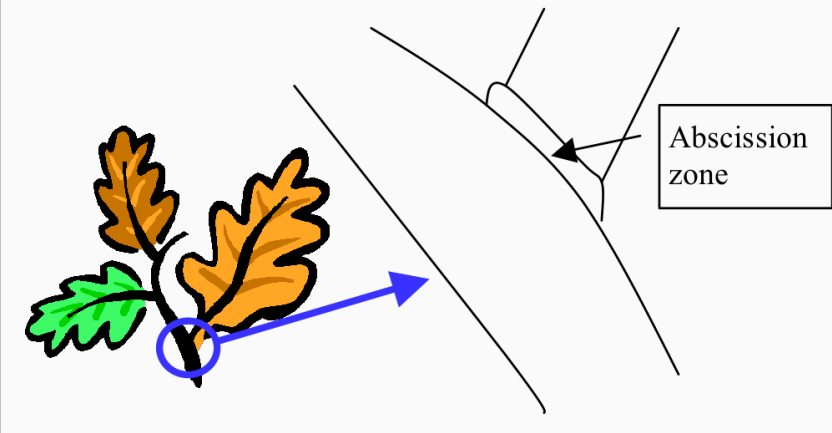

Figure 3: Diagram of abscission zone (Adapted from Purves et al., 2001).

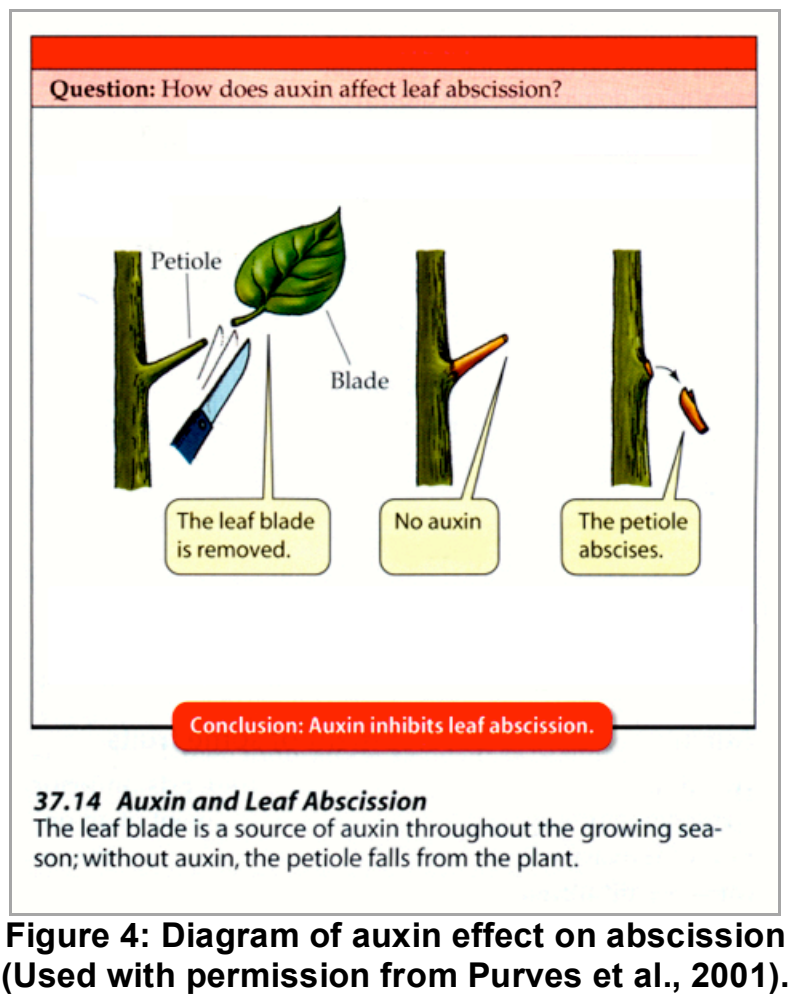

Strategies extracted from biological representations were:

1. Use a sacrificial interfacing part between gripper and screw

2. Regulate the flow of materials

3. Employ a chain of triggers and events

4. Use of chemical adhesives, solvents and/or lubricants

5. The tightening of the object to hold it in place.

Strategies 2 and 3 are not complete because they only contain a portion of a strategy, and are not specific to the biological phenomenon given [Mak and Shu 2004a]. Strategy 4 is classified as incorrect because it results from a misunderstanding of the biological phenomenon given [Mak and Shu 2004a]. The corresponding participants fixated on the term "auxin" (see Figs. 2-4) and mistook it, in one case as a sticky substance that held the leaf in place, and in the other as a type of solvent that breaks down the abscission zone between leaf and stem. Strategy 5 is unrelated to the biological phenomenon because the participant purposely did not use the example provided, contrary to the instructions given, out of the belief that the experimental setup contained some deception.

Strategy 1, the use of a sacrificial part, is identified as correct because it demonstrates an accurate interpretation of one strategy exhibited by the biological phenomenon [Mak and Shu 2004a]. This strategy is the same one that was implemented and tested in the original case study on microassembly [Shu et al. 2006]. Further examples of correct strategies that were not extracted during the study include:

- An appropriately timed removal/release signal

- Removal of a part triggering removal of a subsequent part. 
The concepts were further classified according to their similarity type, and the two concepts that used a correct strategy were also identified as analogies. These correctly mapped, analogous concepts were

1. Use a wax-like material that breaks in shear with increased torque, and

2. Apply a soluble interface material to be dissolved upon release of the screw.

\section{Differences between groups}

Both participants 1 and 2, who were able to extract correct strategies and create analogous designs, were part of the 4participant intervention group. Despite this, in recall interviews these same participants claimed to have found the function structure diagram confusing. The think-aloud session revealed that intervention participant 3 fixated on one box in the diagram, "regulate flow of nutrient/water", used it as an incomplete strategy and created a design by anomaly. Again, the last intervention participant (4) did not attempt to extract any strategy at all, because he suspected some kind of deception was involved in the experiment. That said, the concept developed was strikingly similar to that of participant 3 , where the screw was pinned until tightened. Neither of their solutions addressed sticking while pinning the screw. In the control group, participant 5 did solve the problem, but by anomaly, using an incomplete strategy. His thought process, as is the case with most designs by anomaly [Mak and Shu 2004a], was unclear, even when directly asked to recall and explain it. Control participants 6 and 7 both used strategies that showed an incorrect interpretation of the biological domain.

Figures 5 and 6 show the types of strategies identified and similarities developed by participants. Table 1 categorizes participants' concepts.

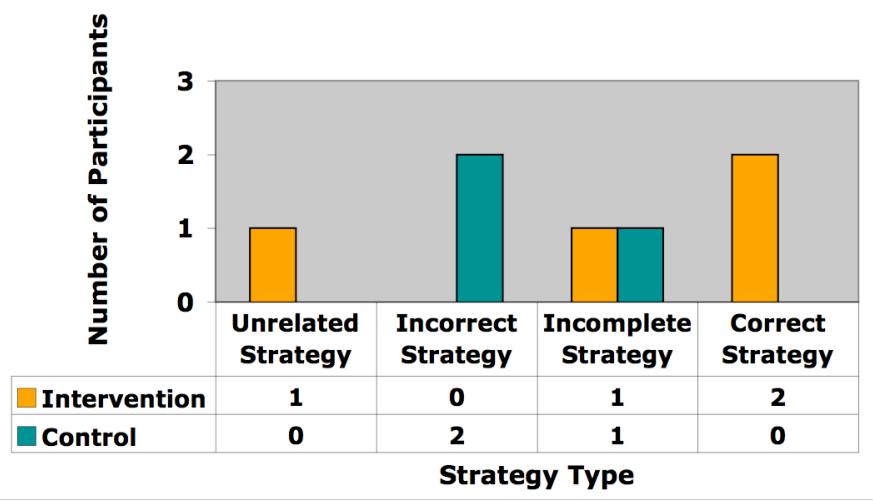

Figure 5: Types of strategies identified.



Figure 6: Types of similarities developed.

Table 1: Categorization of participants' concepts.

\begin{tabular}{|c|c|c|c|c|}
\hline & Analogy & Anomaly & $\begin{array}{c}\text { Literal } \\
\text { Implement. }\end{array}$ & $\begin{array}{l}\text { Bio. } \\
\text { Xfer }\end{array}$ \\
\hline \multicolumn{5}{|l|}{ Correct Strategies } \\
\hline $\begin{array}{l}\text { Use sacrificial } \\
\text { interfacing part }\end{array}$ & $\begin{array}{l}\text { 1. Wax- } \\
\text { like } \\
\text { material } \\
\text { that } \\
\text { breaks in } \\
\text { shear with } \\
\text { increased } \\
\text { torque } \\
\text { 2. Soluble } \\
\text { interface } \\
\text { material }\end{array}$ & & & \\
\hline \multicolumn{5}{|l|}{$\begin{array}{l}\text { Use a removal } \\
\text { signal }\end{array}$} \\
\hline \multirow{2}{*}{\multicolumn{5}{|c|}{\begin{tabular}{l}
$\begin{array}{l}\text { Removal of part } \\
\text { triggers removal } \\
\text { of subsequent } \\
\text { part }\end{array}$ \\
\multicolumn{1}{|l}{ Incomplete Strategies }
\end{tabular}}} \\
\hline & & & & \\
\hline $\begin{array}{l}\text { Regulate flow of } \\
\text { materials (e.g., } \\
\text { nutrients/water) }\end{array}$ & & $\begin{array}{l}\text { 3. Hold } \\
\text { screw } \\
\text { position } \\
\text { with spring- } \\
\text { pin } \\
\end{array}$ & & \\
\hline Chain of events & & $\begin{array}{l}5 . \text { Use } \\
\text { column of } \\
\text { air to pull or } \\
\text { pin screw } \\
\text { depending } \\
\text { on gripper } \\
\text { position }\end{array}$ & & \\
\hline \multicolumn{5}{|l|}{ Incorrect strategies } \\
\hline $\begin{array}{l}\text { Application of } \\
\text { chemical } \\
\text { adhesives, } \\
\text { solvents and/or } \\
\text { lubricants }\end{array}$ & $\begin{array}{l}\text { 6. Apply } \\
\text { adhesive } \\
\text { to surface } \\
\text { of gripper } \\
\text { to grasp } \\
\text { and a } \\
\text { "slippery" } \\
\text { solvent to } \\
\text { release }\end{array}$ & & $\begin{array}{l}\text { 7. Cover grips } \\
\text { with auxin }\end{array}$ & \\
\hline \multicolumn{5}{|c|}{ Unrelated strategies } \\
\hline $\begin{array}{l}\text { Use tightening of } \\
\text { object to hold in } \\
\text { place }\end{array}$ & & $\begin{array}{l}\text { 4. Pin screw } \\
\text { with } \\
\text { screwdriver }\end{array}$ & & \\
\hline
\end{tabular}


In summary, we have the following observations:

- Both correct analogies occurred in the intervention group, suggesting that the function structure diagram may have had some role in the extraction of the correct strategy, despite participants' claims that the intervention was confusing and difficult to map to the biological concept.

- Both incorrect strategies were identified by control group participants, suggesting they did not fully understand the biological phenomenon presented. Both seemed to equate auxin with either an adhesive or solvent produced by the petiole, and not as a signaling agent, which would have been stressed in the function structure diagram.

Before making conclusions, it must be noted that these results come with considerable confounding factors:

- Participant 1, with a correct strategy and analogous concept, had seen the problem and a possible solution during a course taken the previous semester, though he did not report having seen it.

- Participant 7's motivation in participating in the experiment (control group) was questionable. This participant's solution was made well under the allotted time. Effort put into creating a proper solution may have been compromised.

- Background experience of the participants varied greatly and was not accounted for. For example, participant 7, though possessing the same basic undergraduate design knowledge as the others, was currently pursuing a master's degree in a non-design-related branch of operations research. In contrast, participant 1 was a highly motivated senior mechanical engineering student who had selected design-related elective courses.

Some individual differences are noted in the tabulated data in Appendix B. A multi-factor analysis of the effects of motivation, background, and other individual differences would be more revealing.

\section{Common difficulties expressed by participants}

Participants expressed difficulties in that they were unfamiliar with the subject of microassembly. This was intended, in order to have consistency in background knowledge of the problem domain. However, assumptions were required of participants to create design concepts, and the increase in assumptions meant that the problem would have been less consistently understood across participants.

Almost all participants fixated on the word "auxin" at some point during the verbal protocol. Mak and Shu [2004a] also observed that participants tended to fixate on unknown terms. However, providing glossary definitions often caused participants to use contents of the definitions as additional stimuli, as opposed to clarification of the intended stimuli. Fixation was not observed as much on the term "abscission", which was accompanied by detailed pictorial diagrams, but the abscission process itself is the intended stimulus.

Causes of difficulties in designing by analogy, reported by the participants, included:
- Poor understanding/presentation of the problem; this was due to extraneous information, and inconsistencies between the exposition and the problem statement. The challenge of "sticking effects" was not clearly seen by all as the main challenge, rather than the requirement to design a gripper that picks, positions and tightens.

- Poor understanding/presentation of the biological phenomenon; the term "auxin" could have been briefly defined as a hormone or messenger, although those terms may also be misleading or unclear.

- The biological phenomenon does not contain anything analogous to a "gripper", and this was what the design called for.

- Unsuitable representation of function structures.

\section{Discussion}

This section will include the possible implications on the representation of biological phenomena using functional models. This study suggests that a distinction between the extraction of biological strategies and their application should be made. We then make suggestions for the improvement of mapping aids used in this study, and recommend that function structures can play an important role in the development of a biomimetic design process - in the systematic extraction of strategies. The limitations of the study are discussed as a leadin to the section on future work.

\section{Possible implications}

If the strategy is the link that maps the biological phenomenon to the design problem, Figure 7 shows a simple breakdown of the tasks required, as suggested by this study.

Only 2 of the 7 participants extracted a correct strategy from the biological phenomenon, and neither was from the control group. The extraction of the correct strategy from any biological phenomenon, for any given problem is a difficult task. To be done unaided, it requires strong biology knowledge [Vakili \& Shu 2001] or the focused use of working memory [Beveridge \& Parkins 1987].

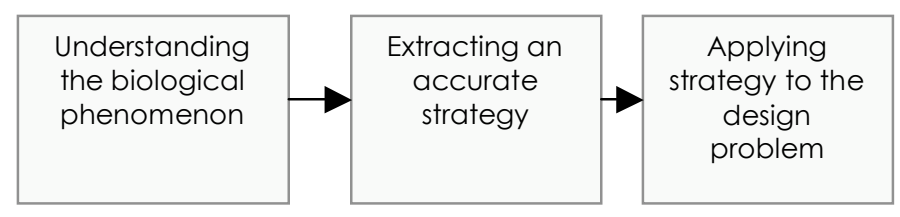

Figure 7: Tasks required in biomimetic design.

Since participants stated they were not able to map the function structure diagram to the biological phenomenon (and seeing the strategy as the bridge between the domains), we conclude that the diagram did not present the possible strategies to them explicitly. The explicit presentation of strategies is needed to improve strategy extraction, and reduce confusion or even rejection of design by analogy. This is a key finding from which further work on functional models can benefit and is discussed in further detail. 


\section{Functional model representation}

Reasons for the difficulties expressed by participants with respect to the function structure diagram included:

1. It was time consuming to decide which flow path is most important, in the case of multiple flows.

2. Having different types of flows in one diagram was confusing.

3. It was difficult to map the function structure representation to the biological system.

The third difficulty seems to be key. If we equate mapping to the task of extracting the strategy, and see extracting as an inherently difficult cognitive task, then we require representations that reduce the cognitive difficulties otherwise added to the design task, and instead make design easier.

Functional models could therefore explicitly present all known correct biological strategies, in order to eliminate the burden on the designer to perform the extractions themselves. Novice designers are not trained to perform the difficult task of extraction of strategies from biological phenomena; to them the process seems complex and prone to error, which can hinder the designer or promote rejection of the new methodology.

This study suggests that function structures could be more effective as an objective method of extracting these strategies, than as a representation tool. Essentially, the functional model would be built independently, and remove the extraction task from the design work. If we provide designers with ready-touse strategies they are perhaps more likely to be employed. In this way, understanding the corresponding biological phenomenon from which they came becomes less critical to the understanding of the strategy itself, and the original text and images become very helpful, unbiased demonstration of the strategy. Our observations suggest these would be most useful if they take the form of images depicting a process, with supporting text [Appendix B].

\section{Improving the task of analogous thinking}

The following is a list of improvements to the task involved in this study, both directly expressed by, and through observations of the participants:

1. To improve understanding of the problem, participants suggested a picture of the microassembly problem because they were unfamiliar with the topic and what solutions might resemble. An appropriate visual aid could be developed that will not bias the design conceptualization. The main problem (analogous to that solved by the biological phenomenon) should be more explicitly highlighted.

2. To improve understanding of the biological phenomenon, the frequency of the use of unknown terms, such as "auxin" (including its use in the title) could have been reduced. Unfamiliar terms could be explained, perhaps by providing a glossary that includes other terms, such that the definition itself would not distract from the main stimuli presented.
3. Though the biological phenomenon did not contain anything analogous to a "gripper", it was hoped that analogous mapping would bridge the lack of explicit similarity. Analogous thinking and strategy extraction needs to be encouraged, through the provided representations, and also perhaps through the instructions given to the participant.

4. The function structure diagram was described by 3 out of 4 intervention participants to be confusing, not helpful, or that they were unable to relate it to the problem. If the strategies are the bridges between biological and engineering domains, these strategies were not made explicit in the function structure diagram. For example, the flow "abscission signal" [Appendix A] might have been made more explicit by identifying the signaling agent, auxin, closely relating it to the strategy "use a removal signal" while reducing misinterpretation of auxin as an adhesive or solvent. One participant suggested merging the function structure diagram with, or superimposing it onto an image of the biological phenomenon itself.

\section{Challenges}

A more natural experimental setting was not possible due to resource availability. Also, an external high-fidelity microphone was not available, but only the one on the video recorder, which increased the difficulty of transcribing participant responses.

This study was intended as a small-scale exploration that would point to directions for further work in the use of functional models in biomimetic design. Further resources are required to design a larger-scale study, with more participants, which would reveal significant effects of individual differences on a number of intervention metrics. With a small sample size, the various problem-solving styles were difficult to separate from the effects of the intervention. The recommendations from this discussion are valuable however, and a necessary first step to reveal next steps in research.

\section{FUTURE WORK}

Future work will focus on 1) objective, systematic strategy extraction through functional modeling, and 2) how to represent these strategies explicitly. The evaluation of these through controlled studies will improve the significance of outcomes. These controlled studies would include complete transcription, encoding or explicit content analysis of the think-aloud sessions. In addition, the relevance and efficiency of the design tool could be evaluated by comparing results between the intervention and control groups.

\section{Objective, systematic strategy extraction}

Future work will focus on the use of function structures as a strategy extraction tool. Formal evaluation of the resulting tool will be key. A graph grammar may be needed to model the extracted strategies in functional representations of biological phenomena. 


\section{Functional model representation}

Explicit strategy representation may still take the form of text descriptions and images, and the manner in which these are presented will affect the designer's understanding of them. The use of applied psychology techniques and practices would add great significance to this type of study and we predict will become quite essential to the research. Human information processing models may add clarity to the challenges to target when developing new representational and functional models.

\section{SUMMARY}

This small-scale exploration, using observation through thinkaloud experiments, as well as direct interviews, has led to suggestions on how to approach functional modeling of biological phenomena. By classifying the designs of 7 participants, and by noting the frequency of common challenges and suggestions, it became clear that both understanding the biological phenomenon and performing the extraction task were very difficult. The function structure diagram seemed to help somewhat in the extraction of correct strategies, however they were still perceived as cumbersome to the participants. It is suggested that function structures be used for objective, systematic extraction of strategies, though not by the designers themselves. Another kind of functional model that can explicitly present these strategies to designers is desirable. The design process studied involves 3 components: understanding, extraction, and application. We recommend that the extraction task be performed by a third party, through systematic means, and not performed by the designer, particularly novices to biomimetic design.

\section{ACKNOWLEDGMENTS}

The authors gratefully acknowledge the Natural Sciences and Engineering Research Council of Canada (NSERC) and the participants of this experiment.

This material is based on work supported by the National Science Foundation under grant NSF-0636411. Any opinions, findings, and conclusions or recommendations presented in this paper are those of the authors and do not necessarily reflect the views of the National Science Foundation.

\section{REFERENCES}

Benami, O., Jin, Y., 2002, Creative Stimulation In Conceptual Design, Proceedings of ASME DETC/CIE, Montreal, Canada, DETC2002/DTM-34023.

Beveridge, M., Parkins, E., 1987, Visual Representation in Analogical Problem-Solving, Memory and Cognition, 15/3:230-237.

Bryant, C., Stone, R., McAdams, D., Kurtoglu, T., Campbell, M., 2005, A Computational Technique for Concept Generation, Proceedings of ASME DETC/CIE, Long Beach, CA, DETC2005/DTM-85323.

Chiu, I., Shu, L., 2004, Natural Language Analysis for Biomimetic Design, Proceedings of ASME DETC/CIE, Salt Lake City, UT, DETC2004/DTM-57250.
Chiu, I., Shu, L.H, 2007, Understanding the Use of Language Stimuli in Concept Generation, Proceedings of ASME IDETC/CIE, Las Vegas, NV, DETC2007/DTM-35772.

Dillon, A., Sweeney, M., 1988, The Application of Cognitive Psychology to CAD, D. Jones and R. Winder (eds.) People and Computers IV, Cambridge University Press, Cambridge.

Gentner, D., 1989, The Mechanisms of Analogical Learning, Similarity and Analogical Reasoning, Cambridge University Press, Cambridge.

Goor, A., Sommerfeld, R.E., 1975, A Comparison of Problem-Solving Processes of Creative Students and Noncreative Students, Journal of Educational Psychology, 67(4), 495-505.

Hacco, E., Shu, L.H., 2002, Biomimetic Concept Generation Applied to Design for Remanufacture, Proceedings of ASME DETC/CIE, Montreal, QC, Canada, DETC2002/DFM-34177.

Hirtz, J., Stone, R., McAdams, D., Szykman, S. and Wood, K., 2002, A Functional Basis for Engineering Design: Reconciling and Evolving Previous Efforts, Research in Engineering Design 13(2):65-82.

Kurtoglu, T., Campbell, M.I., Gonzales, J., Bryant, C.R., Stone, R.B., 2005, Capturing Empirically Derived Design Knowledge for Creating Conceptual Design Configurations, Proceedings of ASME DETC/CIE, Long Beach, CA, DETC2005/DTM-84405.

Mak, T., Shu, L., 2004a, Use of Biological Phenomena in Design by Analogy, Proceedings of ASME DETC/CIE, Salt Lake City, UT, DETC2004/DTM-57303.

Mak, T., Shu, L., 2004b, Abstraction of Biological Analogies for Design, Annals of the CIRP, 53/1:117-120.

McAdams, D., Wood, K., 2000, Quantitative Measures for Design by Analogy, Proceedings of ASME DETC/CIE, Baltimore, MD, DETC2000/DTM-14562.

Purves W.K., Sadava, D., Orians, G.H., Heller, H.C., 2001, Life, The Science of Biology, 6/e, Sinauer Associates, Sunderland, MA.

Shu, L., Hansen, H.N., Gegeckaite, A., Moon, J., Chan, C., 2006, Case Study in Biomimetic Design: Handling and Assembly of Microparts, Proceedings of ASME DETC/CIE, Philadelphia, PA, DETC2006/DTM-99398.

Sridharan, P., Campbell, M., 2004, A Grammar for Function Structures, Proceedings of ASME DETC/CIE, Salt Lake City, UT, DETC2004/DTM-57130.

Stone, R., Wood, K., 2000, Development of a Functional Basis for Design, Journal of Mechanical Design, 122:4/359370 .

Vakili, V., Shu, L.H., 2001, Towards Biomimetic Concept Generation, Proceedings of ASME DETC/CIE, Pittsburg, PA, DETC2001/DTM-21715.

Vincent, J., Mann, D., 2002, Systematic Technology Transfer from Biology to Engineering, Philosophical Trans. Of The Royal Society: Physical Sciences, 360:159-173. 
APPENDIX A

FUNCTION STRUCTURE AS A FUNCTIONAL MODEL OF LEAF ABSCISSION

The following function structure diagram was presented to intervention participants as a functional model of the biological phenomenon.

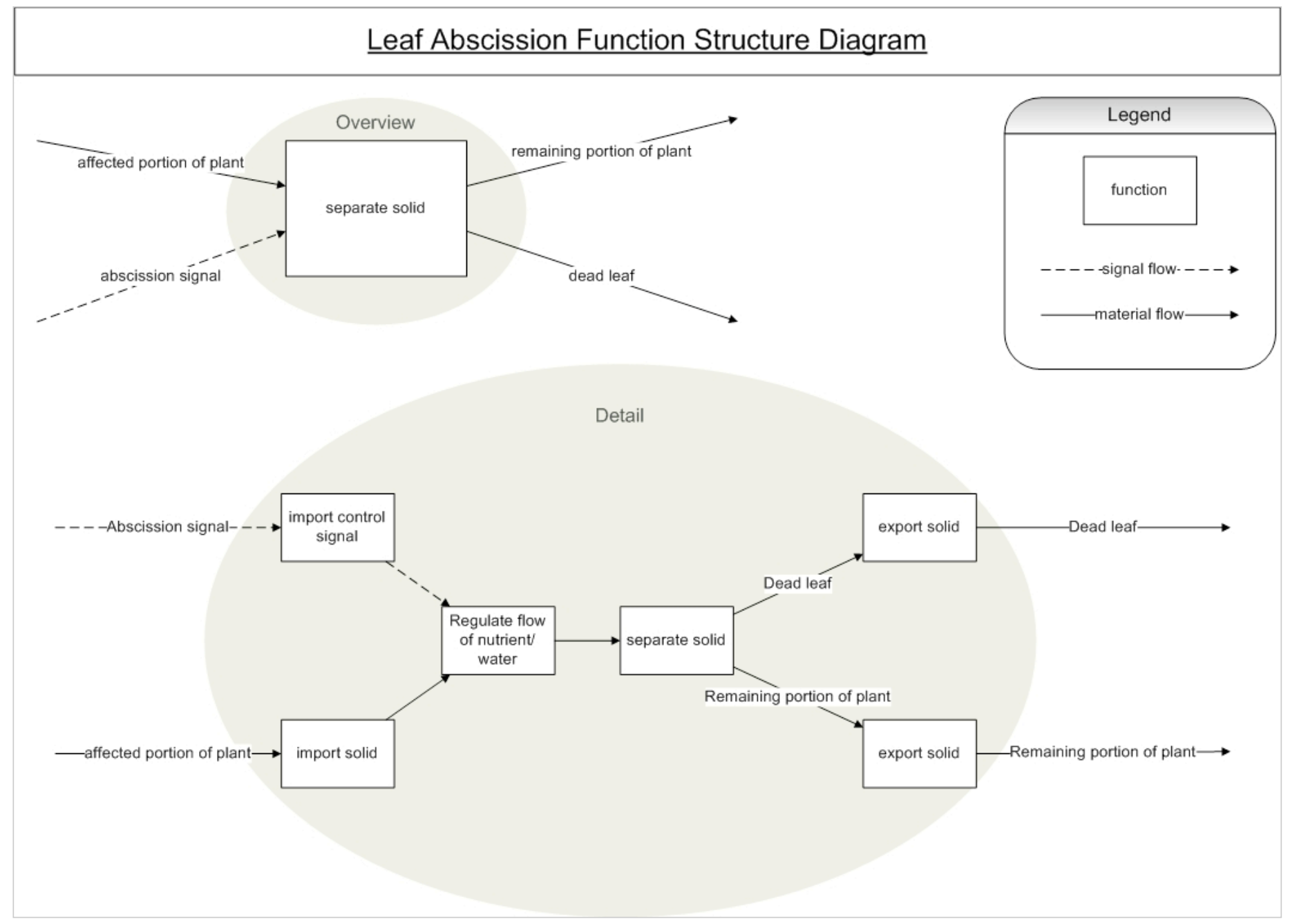


APPENDIX B

TABULATED SUMMARIZED OBSERVATIONS FROM THE STUDY

\begin{tabular}{|c|c|c|c|c|}
\hline Participant & 1 & 2 & 3 & 4 \\
\hline Group & Intervention & Intervention & Intervention & Intervention \\
\hline Experience & 4th year Mech & MASc in Human Factors (HF) & $\begin{array}{l}\text { MASc Autonomous Vehicles, } \\
\text { Control Structures }\end{array}$ & $\begin{array}{l}\text { MASc Hydrogen Fuel } \\
\text { Technology }\end{array}$ \\
\hline $\begin{array}{l}\text { Order of use of } \\
\text { aids }\end{array}$ & Problem, text, images, FS & Problem, images, FS, text & Problem, text, images, FS & Problem, Images, FS, text \\
\hline $\begin{array}{l}\text { Understanding of } \\
\text { Abscission }\end{array}$ & Unsure. & $\begin{array}{l}\text { Correct. Understands that auxin } \\
\text { produced in the blade influenced } \\
\text { the flow of water and nutrients } \\
\text { and cause breakdown. }\end{array}$ & Seems he misunderstood it. & $\begin{array}{l}\text { Correct. Absolutely full } \\
\text { understanding. }\end{array}$ \\
\hline $\begin{array}{l}\text { Interpretation of } \\
\text { Problem }\end{array}$ & $\begin{array}{l}\text { Picking up and overcoming } \\
\text { sticking effects to release part } \\
\text { after tightening of screw }\end{array}$ & $\begin{array}{l}\text { Overcome sticking effects upon } \\
\text { release of screw }\end{array}$ & $\begin{array}{l}\text { Overcome sticking effects upon } \\
\text { release of screw }\end{array}$ & $\begin{array}{l}\text { Design the whole manufacturing } \\
\text { system of picking up, positioning, } \\
\text { tightening. Assumed he didn't } \\
\text { need to address sticking forces if } \\
\text { tightening the screw. If } \\
\text { unscrewing the screw and had to } \\
\text { remove it that would have } \\
\text { changed the nature of the } \\
\text { problem to him. }\end{array}$ \\
\hline Concept & $\begin{array}{l}\text { Screws manufactured with the } \\
\text { interface material on their heads } \\
\text { OR material could be supplied as } \\
\text { a liquid and solidify on contact } \\
\text { with the screw head. This } \\
\text { material breaks off when torque } \\
\text { is exceeded (i.e. screw is } \\
\text { tightened). }\end{array}$ & $\begin{array}{l}\text { Design not developed but had a } \\
\text { concept of interfacing or } \\
\text { separating materials, quickly } \\
\text { breaking down an interface -- } \\
\text { Material which can be originally } \\
\text { attached but very easily removed } \\
\text { from each other. }\end{array}$ & $\begin{array}{l}\text { A gripper with a loaded spring } \\
\text { inside that releases when the } \\
\text { screw is in position. When the } \\
\text { spring hits the screw the gripper } \\
\text { fingers open. When the gripper } \\
\text { arms open, it somehow reloads } \\
\text { the spring. }\end{array}$ & $\begin{array}{l}\text { Feed path; horizontally pivoting } \\
\text { arm, precisely controlled by } \\
\text { servomechanism. Actuators } \\
\text { close over the screw from feed } \\
\text { path, pivots over to position the } \\
\text { screw. Vertical screwdriver } \\
\text { tightens screw. Overcome } \\
\text { sticking forces by having it } \\
\text { pinned by screwdriver during } \\
\text { release of the gripper. }\end{array}$ \\
\hline $\begin{array}{l}\text { Use of Abscission } \\
\text { in Concept }\end{array}$ & Sacrificial part & Breakdown of abscission zone & $\begin{array}{l}\text { Used the general concept of } \\
\text { regulation (i.e. of nutrients and } \\
\text { water) }\end{array}$ & $\begin{array}{l}\text { None. } \\
\text { Only the scale of the example } \\
\text { was analogous. Was aware } \\
\text { something could be missing but } \\
\text { couldn't connect the two domains }\end{array}$ \\
\hline Text and Images & $\begin{array}{l}37.14 \text { helpful by showing a step- } \\
\text { by-step process. } \\
\text { Text helpful. }\end{array}$ & $\begin{array}{l}\text { Found the bio. images and text } \\
\text { most useful. Pictures really } \\
\text { important to understand text } \\
\text { description. Would not have } \\
\text { understood without the diagrams. } \\
\text { Be careful how to highlight the } \\
\text { information in the text, but don't } \\
\text { bias the reader either. }\end{array}$ & $\begin{array}{l}\text { Images did not help solve the } \\
\text { problem, or understand the text. }\end{array}$ & $\begin{array}{l}\text { "They confused me because I } \\
\text { had trouble connecting it to a } \\
\text { microassembly problem." }\end{array}$ \\
\hline $\begin{array}{l}\text { Problem } \\
\text { Statement }\end{array}$ & Went from "generic" to simplified. & $\begin{array}{l}\text { Problem statement is a bit } \\
\text { confusing because the essence } \\
\text { is to design the gripper and its } \\
\text { characteristics, but it sounds like } \\
\text { you need to design [the picking, } \\
\text { positioning, tightening] } \\
\text { mechanism too. }\end{array}$ & $\begin{array}{l}\text { Not completely clear. } \\
\text { Would have liked diagrams of } \\
\text { grippers, example solution. } \\
\text { Problem Statement did not deal } \\
\text { with the same issues identified in } \\
\text { the Challenge section ("because } \\
\text { the tightening has nothing to do } \\
\text { with the background info.") } \\
\text { Size of screw seemed irrelevant. }\end{array}$ & $\begin{array}{l}\text { Clear. } \\
\text { The preamble "Challenge" } \\
\text { section was the most useful of } \\
\text { the aids. } \\
\text { Problem Statement did not deal } \\
\text { with the same issues identified in } \\
\text { the Challenge section. } \\
\text { Did not know anything about the } \\
\text { problem area. }\end{array}$ \\
\hline $\begin{array}{l}\text { Function structure } \\
\text { Diagram }\end{array}$ & $\begin{array}{l}\text { FS was confusing. Complicates } \\
\text { the concept because there was } \\
\text { both material and signal flow. Not } \\
\text { used to seeing more than one } \\
\text { type in a flow diagram. Could not } \\
\text { tie it to } 37.14 \text {. }\end{array}$ & $\begin{array}{l}\text { FS is confusing. } \\
\text { What does separate solid mean? } \\
\text { The signal doesn't jive with the } \\
\text { idea of a plant [did not connect } \\
\text { with chemical messenger } \\
\text { concept]. } \\
\text { Suggestions: Use more vivid } \\
\text { images of the plant on the FS } \\
\text { diagram, or draw the flows on the } \\
\text { actual image of the plant. }\end{array}$ & $\begin{array}{l}\text { Zeroed in on that one "regulate" } \\
\text { box in the FS. }\end{array}$ & $\begin{array}{l}\text { Did not help-seemed } \\
\text { specialized to info. about plants } \\
\text { but not relevant to my problem. } \\
\text { I like diagrams but flowcharts are } \\
\text { like a "choose-your own } \\
\text { adventure" where you don't know } \\
\text { what path is more important. }\end{array}$ \\
\hline $\begin{array}{l}\text { Perceived } \\
\text { motivation }\end{array}$ & High & High & High & High \\
\hline Other Comments & $\begin{array}{l}\text { He has taken the design course } \\
\text { and seen this problem before, } \\
\text { though he may not consciously } \\
\text { remember. } \\
\text { He did not go back to things he } \\
\text { felt he understood. }\end{array}$ & $\begin{array}{l}\text { Thought there was a correct } \\
\text { answer. } \\
\text { It was really difficult for me to see } \\
\text { how [the two domains were } \\
\text { related.] But keywords helped } \\
\text { "the sticking effects, releasing the } \\
\text { micro-objects, that's the } \\
\text { keywords because we are talking } \\
\text { about detachment". }\end{array}$ & $\begin{array}{l}\text { The input/output warm up } \\
\text { exercise influenced his design } \\
\text { process and the FS reinforced } \\
\text { the input/output thinking. }\end{array}$ & $\begin{array}{l}\text { Thought there was deception; } \\
\text { Mentioned that he reads a lot-- } \\
\text { may have led to most thorough } \\
\text { understanding of abscission } \\
\text { compared to others. }\end{array}$ \\
\hline
\end{tabular}




\begin{tabular}{|c|c|c|c|}
\hline $\begin{array}{r}\text { T\& } \\
\text { Participant }\end{array}$ & $\frac{\text { ated Observations }}{5}$ & 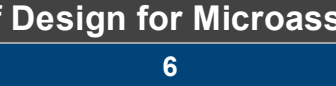 & $\frac{\text { mbly (cont.) }}{7}$ \\
\hline Group & Control & Control & Control \\
\hline Experience & MASc HF Telerobotics & PhD HF Applied Psych; Comp Sci & MASc in Scheduling \\
\hline $\begin{array}{l}\text { Order of use of } \\
\text { aids }\end{array}$ & Problem, text and images & Problem, text and images & Problem, text and images \\
\hline $\begin{array}{l}\text { Understanding of } \\
\text { Abscission }\end{array}$ & $\begin{array}{l}\text { Fair. Only misunderstood that it's } \\
\text { the abscission zone to which } \\
\text { nutrients are restricted, not the } \\
\text { whole petiole }\end{array}$ & $\begin{array}{l}\text { Correct when asked to recite, } \\
\text { however, during the protocol she } \\
\text { equates auxin to a "stickiness } \\
\text { chemical" }\end{array}$ & $\begin{array}{l}\text { Poor. Auxin causes abscission; } \\
\text { thinks auxin is created when a leaf } \\
\text { is cut off [incongruous] }\end{array}$ \\
\hline $\begin{array}{l}\text { Interpretation of } \\
\text { Problem }\end{array}$ & $\begin{array}{l}\text { Overcome sticking effects upon } \\
\text { release of screw }\end{array}$ & $\begin{array}{l}\text { Improve sticking effects upon } \\
\text { grasping and reduce them upon } \\
\text { release of screw }\end{array}$ & $\begin{array}{l}\text { Overcome sticking effects upon } \\
\text { release of screw }\end{array}$ \\
\hline Concept & $\begin{array}{l}\text { Clasp the screw horizontally. To } \\
\text { overcome sticking forces around } \\
\text { perimeter of screw head, use a } \\
\text { vertical column of air to suck up } \\
\text { when the gripper clasps the screw, } \\
\text { then force the air out when } \\
\text { releasing the screw. }\end{array}$ & $\begin{array}{l}\text { Inject/apply "stickiness chemical" } \\
\text { [she equated this to auxin, even } \\
\text { though auxin is not sticky, it is a } \\
\text { signal] to surface of gripper, via } \\
\text { internal tube or external brush } \\
\text { applicator, during grasping. Next } \\
\text { apply a second chemical to cancel } \\
\text { out the stickiness chemical as well } \\
\text { as increase slipperiness. }\end{array}$ & $\begin{array}{l}\text { Covered the grips in auxin } \\
\text { because auxin stops leaves from } \\
\text { sticking, therefore causes } \\
\text { separation. }\end{array}$ \\
\hline $\begin{array}{l}\text { Use of Abscission } \\
\text { in Concept }\end{array}$ & $\begin{array}{l}\text { Make a chain of events that would } \\
\text { allow overcoming the sticking } \\
\text { effects. Nothing happens } \\
\text { independently. The idea of } \\
\text { unexpected events. }\end{array}$ & $\begin{array}{l}\text { Chemical-based solution could be } \\
\text { useful as opposed to mechanical } \\
\text { only }\end{array}$ & Direct transfer, but warped. \\
\hline Text and Images & $\begin{array}{l}\text { Images explain the process of } \\
\text { abscission more. But the title of } \\
\text { the text was misleading because } \\
\text { the first word is "Auxin" }\end{array}$ & $\begin{array}{l}37.14 \text { was most helpful by } \\
\text { showing a step-by-step process } \\
37.13 \text { reinforced the idea of a } \\
\text { surface interface. } \\
\text { Mostly the images just helped } \\
\text { understand the text. }\end{array}$ & $\begin{array}{l}\text { Text was enough to understand } \\
\text { abscission so visual aids were just } \\
\text { supplemental }\end{array}$ \\
\hline $\begin{array}{l}\text { Problem } \\
\text { Statement }\end{array}$ & $\begin{array}{l}\text { Clear. } \\
\text { Didn't know what a traditional } \\
\text { gripper looks like. A picture of } \\
\text { traditional gripper would have } \\
\text { been very helpful. Also a picture of } \\
\text { how the gripper is used in the } \\
\text { problem domain. }\end{array}$ & $\begin{array}{l}\text { Would have definitely liked } \\
\text { supporting diagrams to understand } \\
\text { the problem. } \\
\text { "Challenge" section made it look } \\
\text { like the problem was between the } \\
\text { components [I guess she } \\
\text { understood components as parts } \\
\text { to be manipulated." Misunderstood } \\
\text { the effect of gravitational force. }\end{array}$ & $\begin{array}{l}\text { Would have liked a picture of } \\
\text { microassembly. }\end{array}$ \\
\hline $\begin{array}{l}\text { Function structure } \\
\text { Diagram }\end{array}$ & na & na & na \\
\hline $\begin{array}{l}\text { Perceived } \\
\text { motivation }\end{array}$ & High & High & Low \\
\hline Other Comments & & $\begin{array}{l}\text { She has a good background in } \\
\text { experiment design so she would } \\
\text { have had no problem, even } \\
\text { without the accompanying text. }\end{array}$ & $\begin{array}{l}\text { She did not seem to take much } \\
\text { time to think things through. }\end{array}$ \\
\hline
\end{tabular}

